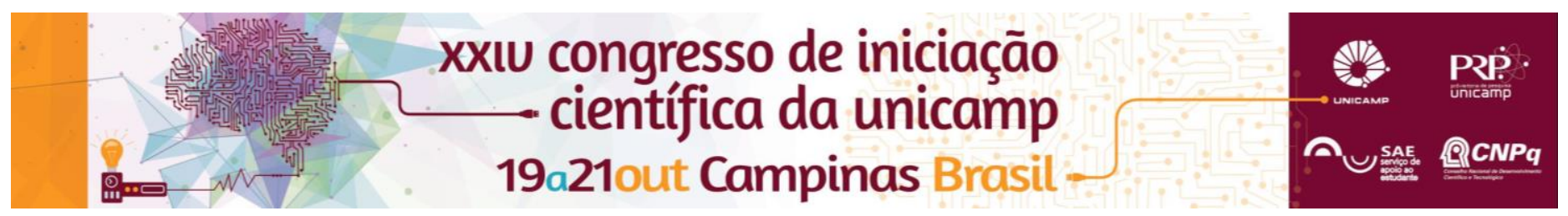

\title{
USO DE HIDROTALCITAS EM COLUNAS DE ADSORÇÃO DE LEITO FIXO PARA PURIFICAÇÃO DE XILITOL
}

\author{
Raquel Dotta*, Priscila H. Carvalho, Marcus B. S. Forte
}

\begin{abstract}
Resumo
Essa pesquisa tem como objetivo aplicar a tecnologia de biosseparação cromatográfica utilizando hidrotalcitas (HDL) como adsorventes, microencapsulados em microgéis de alginato como suporte, para a separação de xilitol de seus contaminantes (xilose e arabinose). O comportamento da adsorção de xilitol (XOL) nas micropartículas de HDL em presença de xilose (XIL) e arabinose (ARA) foi avaliado, usando uma coluna de leito fixo do material adsorvente. Os ensaios foram realizados em triplicata a $25{ }^{\circ} \mathrm{C}$ pelo método de pulso cromatográfico, no qual um pulso de volume conhecido de amostras foi injetado na coluna através da passagem contínua e descendente da fase móvel. Os tempos de retenção e recuperação mássica para o XOL, ARA e XIL foram, respectivamente: $\mu X O L=7,3$ min e RMXOL $=99,6$ $\% ; \mu$ ARA $=6,8$ min e RMARA $=98,5 \% ; \mu X I L=6,6$ min e RMXIL $=95,5 \%$.
\end{abstract}

Palavras-chave: Xilitol; Purificação; Adsorção; Leito fixo.

\section{Introdução}

O xilitol, um poliálcool cuja fórmula molecular é $\mathrm{C}_{5} \mathrm{H}_{12} \mathrm{O}_{5}$, é utilizado como um adoçante natural por apresenta propriedades similares à sacarose, a rápida dissolução na água, tendo ainda um reduzido valor calórico[ ${ }^{[1]}$. Pode ser obtido pela fermentação de Candida guilliermondi que converte xilose em xilitol.

Hidróxido duplo lamelar (HDL) é um sólido mineral, em forma de pó, que vem se destacando quanto ao potencial de adsorção de ânions ${ }^{[2]}$. Os HDL mais conhecidos e utilizados são os compostos do tipo da hidrotalcita ${ }^{[3]}$ que podem ser utilizadas como recheio em coluna de leito fixo para a purificação de compostos. Porém, a propriedade de intumescimento em solução aquosa impossibilita seu uso em colunas de leito fixo devido a obstrução do leito. A microencapsulação dos HDL em microgéis de alginato se apresenta como uma medida interessante para viabilizar o uso de HDL em leitos empacotados.

Tendo em vista que a maior limitação da utilização do xilitol é devido ao seu alto custo, que cerca de $90 \%$ do custo total da produção de uma biomolécula pode estar associado à etapa de purificação e considerando os baixos custo da utilização de HDL, a utilização da técnica de microencapsulação, aliada ao potencial dos HDL como adsorventes, representa uma ferramenta interessante para a utilização desse material em colunas de biosseparação cromatográfica para a separação de xilitol de seus contaminantes.

\section{Resultados e Discussão}

Pode-se observar que a metodologia escolhida produziu microesferas de hidrotalcita com características e distribuição uniformes, com alginato na parte exterior e hidrotalcita em seu interior, possibilitando, quando usada como adsorvente, um fluxo de fase móvel ao longo da coluna. Em seguida, foram realizados testes, em triplicata, de adsorção em coluna de leito fixo com soluções puras de xilitol e contaminantes (xilose e arabinose) em concentração de $200 \mathrm{~g} / \mathrm{L}$, onde a temperatura foi mantida a $25^{\circ} \mathrm{C}$, com volume de injeção $\mathrm{Vi}=1,0 \mathrm{~mL}$ das soluções puras, e utilizando como fase móvel água deionizada com $\mathrm{CaCl}_{2}(0,05 \mathrm{M})$ e azida $(0,005 \mathrm{M})$ com vazão de 1,27 $\mathrm{cm} / \mathrm{min}$. Os experimentos foram conduzidos com duração de 50 min e coleta de frações de amostra a cada $1 \mathrm{~mL}$. A concentração das amostras foi analisada por refratometria (grau Brix). A partir da concentração foi calculado o tempo de retenção $(\mu)$ e a taxa de recuperação mássica (RM). Os testes de absorção com xilitol (XOL), arabinose (ARA) e xilose (XIL), respectivamente, apresentam os seguintes resultados: um $\mu \mathrm{XOL}=7,3$ min e $\mathrm{RMxOL}=99,6 \pm 0,3 \%$; $\mu_{\text {ARA }}=6,7$ e RMARA $=98,5 \pm 0,3 \% ; \mu x I L=6,6$ min e RMxIL $=95,5 \pm 0,3 \%$. Pode-se observar que os tempos de retenção para XOL, ARA e XIL, são próximos. Este fato pode ser explicado considerando os pesos moleculares das substâncias utilizadas, que são muito semelhantes, ocupando os mesmos sítios dentro da coluna e liberadas em tempos semelhantes de retenção.

\section{Conclusões}

As microesferas de HDL apresentaram distribuição uniformes e possibilitando um fluxo de fase móvel ao longo da coluna. As hidrotalcitas são interessantes para purificação de xilitol, já que foram obtidas boas recuperações do bioproduto (> $99 \%$ ). No entanto, foi obtida uma separação discreta, o que pode ser melhorado através da variação dos parâmetros operacionais, tais como: temperatura, altura do leito, vazão de alimentação, volume de injeção e em diferentes fases móveis (etanol), o que será feito na sequência do projeto.

\section{Agradecimentos}

Ao CNPq pelo apoio financeiro.

\footnotetext{
${ }^{1}$ WINKELHAUSEN, E. and KUZMANOVA, S. Microbial conversion of Dxylose to xylitol. Journal Ferment Bioeng, v. 86, p. 1-14, 1998.

${ }^{2}$ YANG, L.; DADWHAL, M.; SHAHRIVARI, Z.; OSTWAL, M.; LIU, P. K. T.; SAHIMI, M.; TSOTSIS, T. T. Adsorption of arsenic on layered double hydroxides: Effect of the particle size. Ind Eng Chem Res, v. 45, p. 4742-4751, 2006

${ }^{3}$ JAFARI, S. M.; ASSADPOOR, E.; HE, Y.; BHANDARI, B. Encapsulation Efficiency of Food Flavours and Oils during Spray Drying. Drying Technology, 26:7, 816-835, 2008.
} 